www.jmscr.igmpublication.org

Impact Factor (SJIF): 6.379

Index Copernicus Value: 71.58

ISSN (e)-2347-176x ISSN (p) 2455-0450

crossref DOI: _https://dx.doi.org/10.18535/jmscr/v6i4.161

Journal Of Medical Science And Clinical Research

IGM Publication

An Official Publication of IGM Publication

\title{
Retro-peritoneal Laparoscopic Ureterolithotomy for Proximal Ureteral Stones: An Experience from a Tertiary Care Institute from Kashmir Valley
} Authors

\section{Zahid Mohd Rather ${ }^{1}$, Mohd Nazrull Islam², Imran Nazir Mir ${ }^{3}$, Nighat Ara Majid², Raja Waseem Mohd ${ }^{4}$}

${ }^{1}$ Senior Resident, Post Graduate Department of General and Minimal Access Surgery, Govt. Medical College Srinagar, Jammu \& Kashmir, India

${ }^{2}$ Junior Resident, Post Graduate Department of General and Minimal Access Surgery, Govt. Medical College Srinagar, Jammu \& Kashmir, India

${ }^{3}$ Senior Resident, Division of Urology, Post Graduate Department of General and Minimal Access Surgery,

Govt. Medical College Srinagar, Jammu \& Kashmir, India

${ }^{4}$ Senior Resident, Post Graduate Department of Radio-diagnosis\& imaging, Govt. Medical College

Srinagar, Jammu \& Kashmir, India

Corresponding Author

Zahid Mohd Rather

Postal add: Married Hostel, opposite to SMHS causality, room no. C18, karan Nagar Srinagar, pin 190010 Contact No: 09469784774, Email: drzahidmrather@yahoo.com

\begin{abstract}
Background: Currently, shock wave lithotripsy (SWL), ureteroscopy (URS) and HO:YAG laser are the first line of treatments for patients with ureterolithiasis requiring surgical management. At centers which don't have access to expensive equipment needed in URS and SWL, Laparoscopic ureterolithotomy may be used as a primary procedure. The aim of this study is to share our experience of retroperitoneal laparoscopic ureterolithotomy for proximal ureteric calculi and evaluate the safety and efficacy of this procedure.

Material and Methods: This prospective study was conducted from March 2011 to August 2017 at our centre. A total of 94 patients with proximal ureteric stone who accepted laparoscopic ureterolithotomy were enrolled in the study. The evaluation and assessment of all these patients was done on the OPD basis with reference to their indication and suitability for laparoscopic ureterolithotmy modality of treatment.

Results: The mean age was 37 years. There were 61(64.89\%) males. The stones were located in the right side in 58(61.70\%) patients. 66(70.21\%) patients have upper ureteral stone and $28(29.78 \%)$ patients have middle ureteral stones. The average stone size was $14.5 \mathrm{~mm}$. Various complications that occurred during the procedure were difficulty in ureter localization, bleeding, injury to peritoneum, stone migration, and urinary leakage. The mean operative time was 65 minute and the mean blood loss was $70.50 \mathrm{ml}$. Mean hospital stay was 2.1 days and the stone clearance was $92(97.87 \%)$.

Conclusion: Even though SWL and URS are considered to be the first-line treatment for ureteral stones, retroperitoneal laparoscopic ureterolithotomy is a very effective minimally invasive modality of treating ureteral calculi. Unlike URS this procedure can give 100\% stone clearance in one session. Although its role as a salvage procedure for failed ESWL, and ureteroscopy is undisputed, in selected patients with large chronically impacted ureteric stones, it may be considered the first line of treatment.

Keywords: Uteric calculus, Retro-peritoneal laparoscpy, ureterolithotomy.
\end{abstract}




\section{Introduction}

The life time incidence of urolithiasis is up to 15 $\%$ in males and $8 \%$ in females with a yearly incidence of around 131 per 100,000. The life time recurrence rate in patients with known urolithiasis approaches $50 \%$. Even today most of these patients are still handled by surgeons ${ }^{[1]}$. Currently, shock wave lithotripsy (SWL), ureteroscopy (URS), and HO: YAG laser are the first line of treatments for patients with ureterolithiasis requiring surgical management ${ }^{[2]}$. However, their use for large upper and middle ureteral stones remains controversial ${ }^{[3]}$. Particularly with impacted stones, the success rate of SWL and URS diminishes, and when the stone size exceeds $1 \mathrm{~cm}$, SWL efficacy decreases to from 84 to $42 \%^{[4]}$. However $7 \%$ of patients with ureteral stones may require repeated sessions of SWL, $1 \%-10 \%$ of such patients may need open surgery $^{[5]}$. At centers which do not have access to expensive equipment needed in URS and SWL, laparoscopic ureterolithotomy may be used as a primary procedure. The patients who are otherwise candidates for open surgery constitute the target population that may benefit from laparoscopic surgery in reducing morbidity and hastening recovery. Laparoscopic ureterolithotomy is gaining popularity for the management of upper ureteric stones especially if the stone is big or may require many endoscopic procedures and SWL sessions. Although laparoscopic ureterolithotomy (LU) is not the first choice in most cases for its invasiveness, LU has the highest stone-free rate (SFR) compared to SWL and URS, and LU also has its unique advantages on patients with large impacted stone, severe hydronephrosis, or anatomic anomalies ${ }^{[6]}$.

\section{Material and Methods}

The study titled "Retro-peritoneal Laparoscopic Surgery in the management of proximal uereteric stones: An experience from a tertiary care institute from Kashmir Valley" Was under taken in the Post Graduate Department of General and Minimal Access Surgery, Govt. Medical College
Srinagar. The study was completed from March 2011 to August 2017. A total of 94 patients were enrolled in the study. It was prospective observational study. An informed consent was obtained from the patients. Patients presenting with symptomatic proximal ureteric stones were included in the study lot. The diagnosis was established by ultra-sound, KUB, IVU and CT Urography in some patients [ Figure 1].Patients with bilateral stones, having previous retroperitoneal surgery and those unfit for general anesthesia were excluded from the study.The indications for LU were a stone $>15 \mathrm{~mm}$ in diameter in upper or midureter or a history of failed SWL or URS. All lower ureteric stones were managed by URS. All procedures were performed by an experienced laparoscopic surgeon. All patients were followed up for at least 3 months. The study sample of patients was evaluated by detailed history, thorough general physical examination, and focused systemic examination and by metabolic profile. Informed consent was taken from all patients after explaining various available modalities of treatment with their potential benefits and possible risks. The patients were kept fasting over night and morning KUB was advised in all patients before surgery. All patients received a prophylactic dose of injection of ceftriaxone $1 \mathrm{gm}$ 1 hour before surgery.

\section{Operative techniques}

General anesthesia with Endo-tracheal intubation is used in all Patients. After catheterization the patients are placed in right or left Standard full flank (lateral decubitus) position depending on the side involved. The patients were usually managed by the standard technique of 3 ports. The first port was made distal and anterior to the $12^{\text {th }}$ rib in mid axillary line by designing $1.5 \mathrm{~cm}$ incision the artery clip was used to open up the retroperitoneal space by splitting and lumbo-dorsal fascia. We used balloon dissection in some patients and in others we used finger dissection to develop the space. The other 2 ports $5 \mathrm{~mm}$ and $5 / 10 \mathrm{~mm}$ were made either finger guided or video 
guided. The Hassan's cannula was fixed in the camera port and secured with 2 -0 Vicryl sutures to avoid gas leak. Two $5 \mathrm{~mm}$ ports were created anterior and lateral to this $10 \mathrm{~mm}$ optical port. However the $5 \mathrm{~mm}$ port made $5 \mathrm{~cm}$ above and anterior to the anterior ileac spine was changed to $10 \mathrm{~mm}$ port in most of patients, as gauze insertion and a big stone removal becomes feasible through $10 \mathrm{~mm}$ port. Fourth $5 \mathrm{~mm}$ port (accessory port) for retraction if needed is positioned usually between telescopic port and the port near anterior superior iliac spine. We precisely identified the Psoas muscle and located the ureter running all along its medial boarder. Ureter is identified by its peristaltic activity and anatomical position. The stone was detected easily in majority of patients creating a dumb-bell appearance with the proximal ureter distended and the distal ureter collapsed. The longitudinal ureterotomy was made either by using harmonic ace, mono-polar hook or by Endo knife and stone was sandwiched out between 2 working instruments. The flushing was done by either the ureteric catheter or by feeding tube proximally and distally. The DJ stent was mounted on a guide wire and a pusher and the assembly was loaded in to the lumen of suction tip. The stent was introduced by the left hand of the surgeon and guided by the right hand. Using 4-0 vicryl the ureterotomy was closed in all patients by interrupted intra-corporial suturing. The stones were removed through the $10 \mathrm{~mm}$ working port using stone scoop forceps. . A drain was put in all patients. The ports were closed and dressing applied. On the $1^{\text {st }}$ postoperative period a plain X-Ray KUB was performed to check the status of stent and any residual stone bit left over. The catheter was always removed first followed by drain. The patients were discharged usually between 3 to 7 days postoperatively. The patients were advised to come for follow up and removal of DJ stent was done usually after 6 weeks (Figure. 2 to 6).

Statistical Analysis: The present study was used in descriptive and observation analysis technique for the purpose of study.

\section{Results}

The prospective analytic observational study of, "Retro-peritoneal laparoscopic ureterolithotomy for proximal ureteral stones: An Experience from a tertiary care institute from Kashmir valley." was carried out in the post graduate department of General and minimal access surgery Government medical College Srinagar from March 2011 to August 2017. A total number of 94 patients were evaluated with reference to aims and objectives mentioned, by analyzing the collected data from them. The age of patients ranged from 17-70 years with mean age 37 years. Our study reflected that males were mostly affected to the tune of and 61(64.89\%), Females 33(35.10\%). In majority of patients stone were located in the right side $58(61.70 \%)$ and in left side 36(38.29\%). Majority of patients $66(70.21 \%)$ have upper ureteric stone and $28(29.78 \%)$ have mid ureteric stone. The size of the stones varied from 12 to $25 \mathrm{~mm}$ among the patients; the mean stone size was $14.5 \mathrm{~mm}$ Table 1.

The complications that we faced were difficulty in ureter localization $4(4.25 \%)$ which were managed by conversion to open surgery, bleeding $4(4.25 \%)$, injury to peritoneum 3 (3.19\%), conversion to open $6(6.38 \%)$, stone migration $2(2.12 \%)$, urinary leakage $3(3.19 \%)$, port infection4(4.25\%), sepsis2 (2.12\%) and stent migration1(1.06\%), ureteral stricture 2(2.12) Table2.

In our study group the mean operative time was 65 minutes (range 45-90 minutes), and mean blood loss $70.30 \mathrm{ml}$ (range 30-120 ml), resumption of oral intake was done early as in other laparoscopic surgeries and was average 1.1 days (range 1-2 Days), removal of Foleys catheter was done first followed by removal of drain. Foleys catheter was removed on an average of 1.1 days (range 1-6 days) and drain 1.2(range27 days). The mean hospital stay was 2.1 days (range 2-7days).To check any residual stone and stone clearance, X Ray KUB was done on $1^{\text {st }}$ post operative days. The complete clearance was done in $92(97.87 \%)$ patients Table 3. 
Table 1 Demographic Data

\begin{tabular}{lc}
\hline Variables & Results \\
\hline Patient (N) & 94 \\
Mean age (years),Range & $37(17-70)$ \\
Sex & \\
Male & $61(64.89 \%)$ \\
Female & $33(35.10 \%)$ \\
Stone location & \\
Right & $58(61.70 \%)$ \\
Left & $36(38.29 \%)$ \\
Stone site & \\
Upper & $66(70.21 \%)$ \\
Middle & $28(29.78 \%)$ \\
Lower & $00(00.00 \%)$ \\
Stone size(Average),mm & $14.5(12-25)$ \\
\hline
\end{tabular}

Table 2 Peri and Postoperative Complications

\begin{tabular}{lc}
\hline Complications & $\mathrm{N}=94$ \\
\hline Difficulty in ureter localization & $4(4.25 \%)$ \\
Bleeding & $4(4.25 \%)$ \\
Injury to peritoneum & $3(3.19 \%)$ \\
Transfusion & $0(0 \%)$ \\
Major Vessel Injury & $0(\%)$ \\
Conversion to open & $6(6.38 \%)$ \\
Stone migration & $2(2.12 \%)$ \\
Urinary leakage & $3(3.19 \%)$ \\
Port Infection & $4(4.25 \%)$ \\
Sepsis & $2(2.12 \%)$ \\
Stent migration & $1(1.06 \%)$ \\
Ureteral Stricture & $2(2.12)$ \\
\hline
\end{tabular}

Table 3 Postoperative Variables

\begin{tabular}{lc}
\hline Variables & Results \\
\hline Mean Operative Time, Min & $65(45-90)$ \\
Mean Blood Loss, ml & $70.50(30-120)$ \\
Resumption to Orals intake, Days & $1.1(1-2)$ \\
Removal of Foleys Catheter, Days & $1.1(1-6)$ \\
Removal of Drain, Days & $1.4(1-7)$ \\
Hospital Stay, Days & $2.1(2-7)$ \\
Stone Clearance & $92(97.87 \%)$ \\
\hline
\end{tabular}

\section{Intra-operative figures}

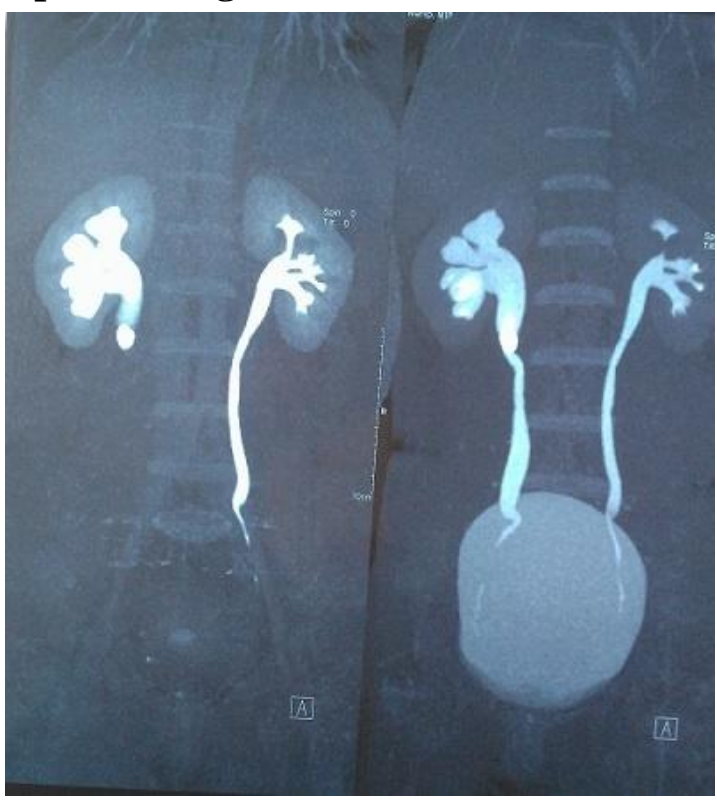

Figure 1 CT Urography of patient showing calculus in right upper ureter

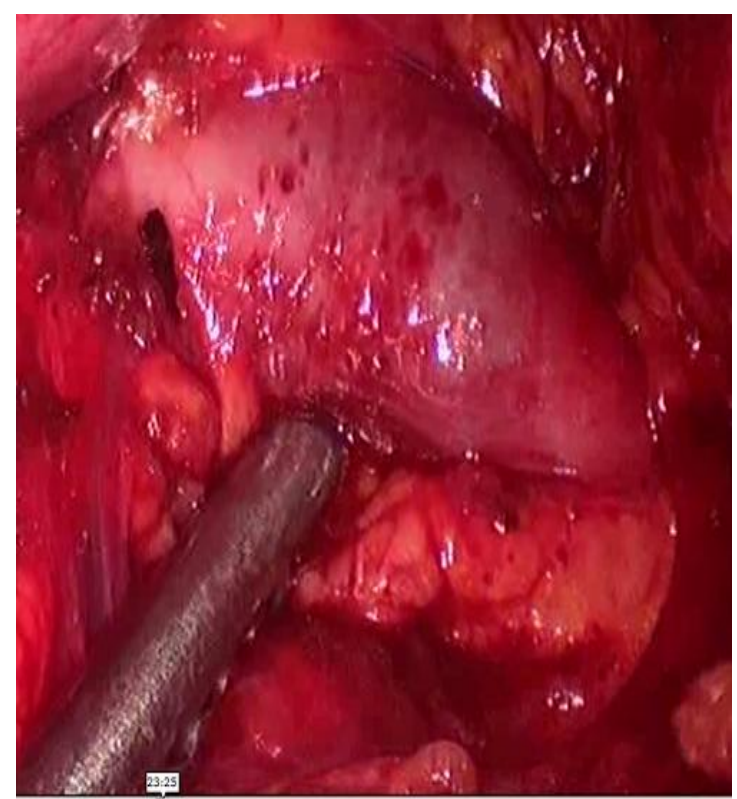

Figure 2 calculus in ureter identified 


\section{JMSCR Vol||06||Issue||04||Page 982-989||April}

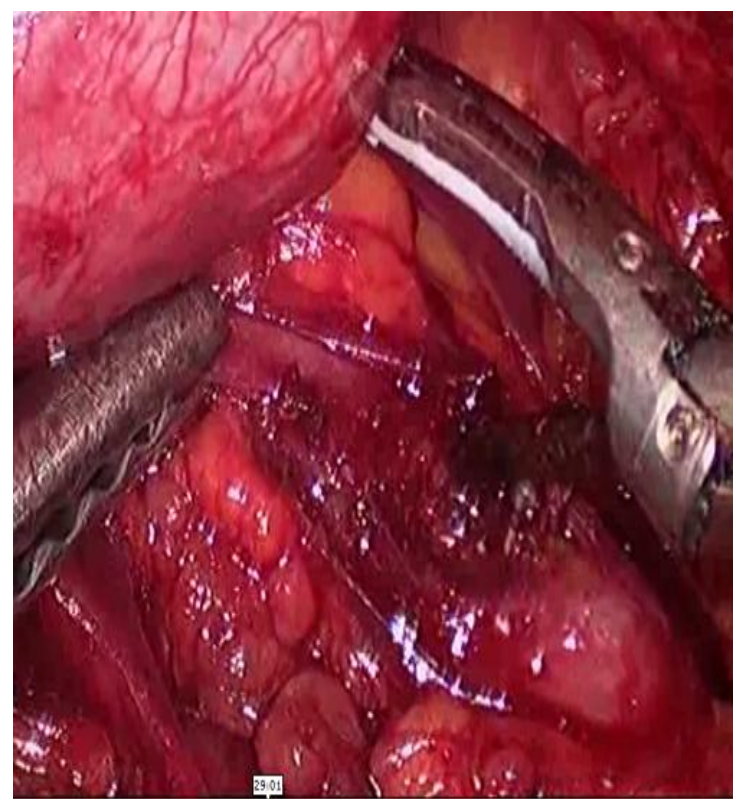

Figure 3 ureterotomy

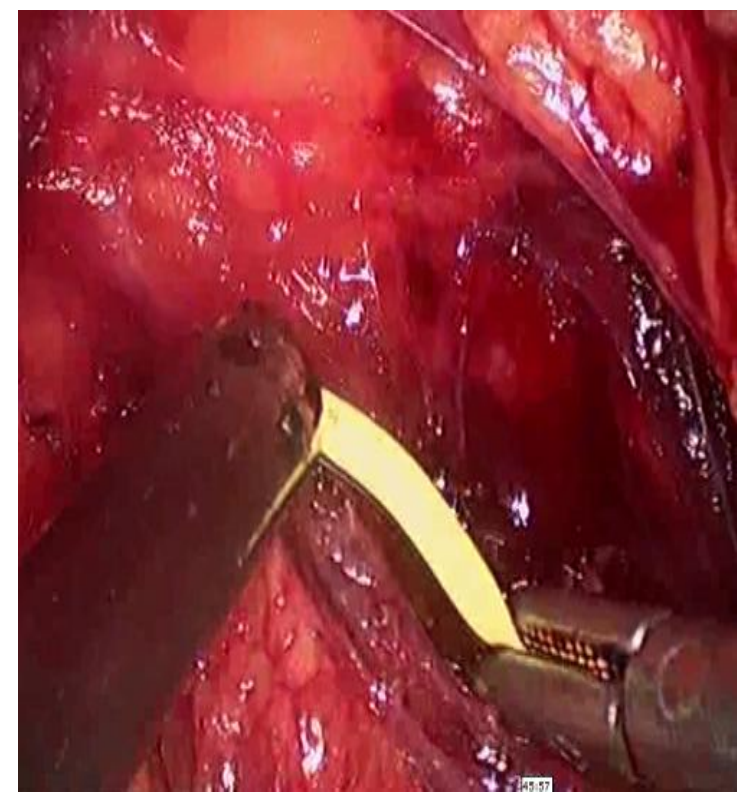

Figure 5 DJ stenting

\section{Discussion}

The treatment of ureteral calculi has evolved in recent decades and the ultimate objects are clearance and minimal invasion. Current options including SWL and URS have the particular rates of clearance; complications, and limitations, respectively. ESWL is suitable for managing ureteric stones of less than $1 \mathrm{~cm}$ in size. With the increase in stone size the chances of stone clearance decreases and the need for multiple sessions increases which together tells upon the patient compliances and adds cost to the treatment [4].

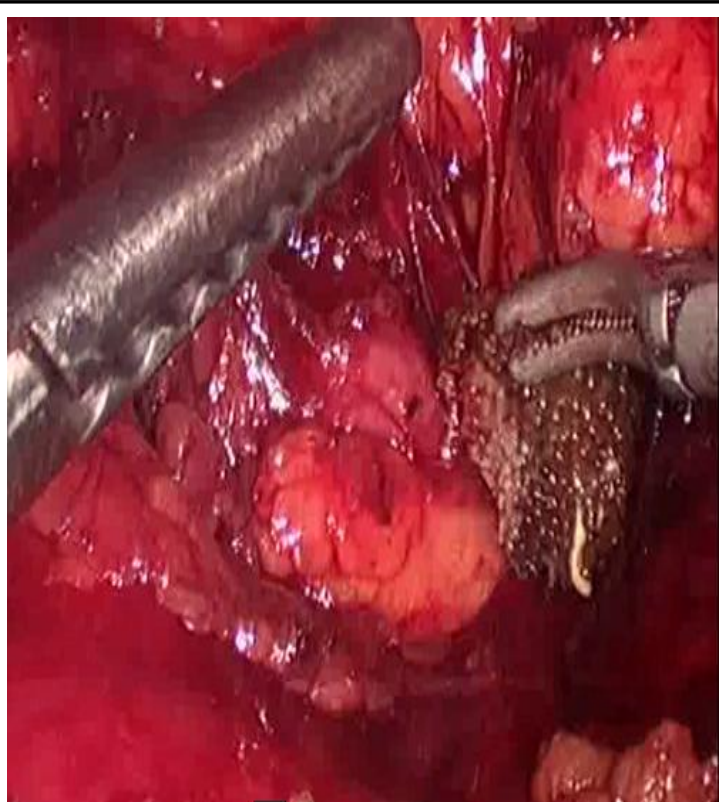

Figure 4 Retrieved uretric calculus

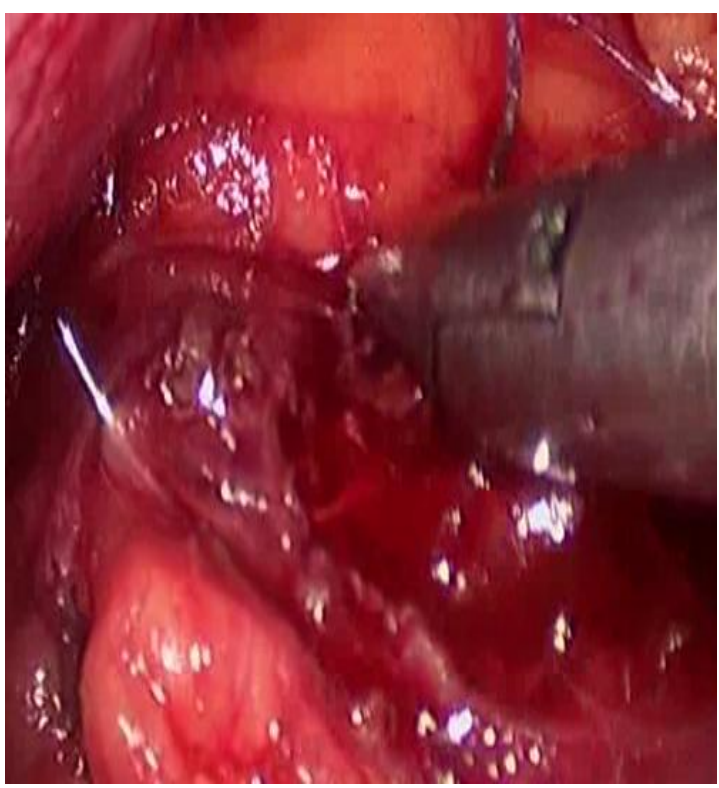

Figure 6 Closure of ureterotomy

The first retroperitoneal ureterolithotomy was performed in 1979 by Wickham ${ }^{[7]}$. In several studies LU showed a $>95 \%$ success rate in the treatment of large ureter stones ${ }^{[8,9]}$ According to the European Association of Urology guidelines on urolithiasis, large impacted ureteral stones, failure of minimally invasive procedures, different operative requirements for a concurrent indication, and technological deficiency are considered to be indications for performing $\mathrm{LU}^{[10]}$. laparoscopic ureterolithotomy occupies the central and dominant place as it is the minimally invasive procedure of choice in a selected group of patients 
were the stone cannot be accessed ureteroscopically or were stones cannot be fragmented.

We took up a study with 94 patients presenting with upper and mid ureteric stones and performed laparoscopic retro-peritoneal ureterolithotomy on all of them. There was the significant learning curve in our performance and took us more than first 15 cases to grasp the technique. The analysis of our series showed that mean age was 37 years (range 17-70 years) and males were predominantly $61(64.89 \%)$ involved in the renal calcular disease $61(64.89 \%)^{[11]}$. We also evaluated the data and found that the presentation of stone and the location was predominantly on the right side to the tune of $58(61.70 \%)$ and $36(38.29 \%)$ on the left $\operatorname{side}^{[12]}$. In our study group upper ureteric stone was present in 66(70.21\%) and lower ureteric stone in $28(29.78 \%)$. The average stone size $14.4 \mathrm{~mm}$ (range 12-25mm) [Table 1]

No surgery is devoid of complications so did we have in our series. In the first few cases we had difficulty in ureter localization 4(4.25\%). As we progressed during our learning curve with the grasp of technique this problem was solved subsequently. Dissection for ureteric localization should be done very much carefully as during this step one may injure gonadal vessels or even IVC and aorta if dissection is carried too medially. During dissection one should avoid sweeping in caudal to cranial direction as it can cause proximal stone migration. We have proximal stone migration in $2(2.12 \%)$ in to the dilated pelvic calyceal system and this patient was converted to open managed thereof. This happened in the beginning of the study during our learning curve. Subsequently we learned that in upper ureteric stones one should always hold the proximal dilated ureter above the stone with a soft non traumatic grasper before making ureterotmy. The study conducted by Selcuk Sahin et al reported higher stone migration rate $(11 \%)$ as compared to our study. Inadvertent peritoneal injury is one of the technical mishaps which can make the procedure difficult by significantly reducing the working space. In our series 3(3.19\%) patients developed this complication. The best way to manage this complication is by introducing Veress needle in the peritoneal cavity. In some cases one may need to enlarge the peritoneal tear to equalize the Pressures ${ }^{[13]}$. The bleeding was present in $4(4.25 \%)$ and we didn't encounter any major vessel injury thereby no transfusions were required in any patient. The conversion rate in our study was $6(6.38 \%)$ Compared to several series that reported conversion rates of $<10 \%[14,15,16,17]$. The reasons for our conversion to open were mostly due to tear in the peritoneum resulting in the collapse of space, ureter localliztion and occasionally for bleeding.

We routinely stented all patients and also sutured ureterotmy with vicryl 4-0 in all patients. This helped us to reduce the prolonged urinary leakage in the post operative period which otherwise increases the morbidity and the hospital stay, though it will increase operative time.3 (3.19\%) patients in our study developed prolonged urinary leak. This was probably in patients were it was difficult to close the pelvis and ureter water tight [18]. Urinary loss of $2-20 \%$ is reported in the literature $^{[15,18,19,20,21] \text {. All these were managed }}$ conservatively. It is important to mention that the patients who had prolonged urinary leakage were discharged from the hospital with an advice to report back after the drain output would substantially would decreased. The port site infection was present in $4(4.25 \%)$ These patients were managed by culture sensitivity specific antibiotics and daily dressing. Sepsis is part of any surgical procedure and we encountered it in $2(2.12 \%)$ cases, possibly due to urinary tract infection or prolonged surgery in these cases which might also be due to port infection. The technique of stenting was practiced meticulously in all patients however in $1(1.06 \%)$ patient we found the stent had curled in the lower ureter. Luckily it didn't pose any post operative problem but it needed Ureteroscope for removal in the third post operative week by the urologist. In follow up period Ureteric stricture was present 
$2(2.12 \%)$ which were managed by ballon dilatation [Table 2].

The mean operative time in our study is $65 \mathrm{~min}$ (45-90). The operative time steadily decreases with increasing experience. Goel et al ${ }^{[13]}$ reported a mean operative time of 108.8 minutes (range 40275 minutes). Hemal et $\mathrm{al}^{[22]}$ reported a mean operative time of 67 minute (range 40 -97 minutes). Flasko et $\mathrm{al}^{[20]}$ reported the shortest mean operative time of 45 minutes (range 15-100 minutes). It is important to mention that one has to be skilled in the technique of port making, establishing a space, localizing the pelvis and ureter, stent insertion and intra corporeal suturing. The blood loss is a part of all surgical procedures but luckily in our series we had a negligible blood loss amounting to mean 70.50 (30-120). While as study conduct by Gaur et al has a mean blood loss of $25 \mathrm{ml}$ (range $5-100 \mathrm{ml}$ ). Goel et $\mathrm{al}^{[13]}$ had a mean blood loss of $58.5 \mathrm{ml}$ (range 25-75ml). In our study we start orals in majority of patients in $1^{\text {st }}$ post operative day; the mean start of orals was 1.1 day (range 1-2 day). It was our standard to remove the Foleys catheter on $1^{\text {st }}$ postoperative day and if there is no increase in urinary drainage after 12 hours, we remove the retroperitoneal drain. The mean duration of removal of Foleys catheter was 1.1(range 1-6days) and drain1.4 (range 1-7 days). The mean hospital stay in our study is 2.1(2-7)) days. Goel et $\mathrm{al}^{[13]}$ reported hospital stay ranging from 2-14 days, with an average hospital stay of 3.3 days. Hemal et $\mathrm{al}^{[22]}$ has a mean hospital stay of 2.4 days range 2-3 days. The short hospital stay which we could offer to these patients we believe is due to using stent in all cases and closing the ureterotomy. Early start of oral feeds on the day of surgery and early removal of Foleys catheter and drain

All patients had to undergo an X-Ray KUB in the first post operative period to access the status of the stent and any residual stone left over. We are satisfied with the stone clearance $92(97.87 \%)^{[5,13]}$ This was possibly because we took care while delivering the stone either from the pelvis and either from the ureter and didn't allow it to break.
It is also because we selected solitary stone patients whether pelvic or ureteric. It is also because proper flushing was performed and also possibly an inherent benefit of laparoscopy that provides a visual guide to remove the stone in Toto.

\section{Conclusion}

We conclude from our study that Endoscopic management takes a lead in the management of urinary calcular disease. Even though SWL and URS are considered to be the first-line treatment options for ureteral stones, retroperitoneal LU can be established as an effective, safe , minimally invasive and reliable method, particularly in cases with large impacted stones and failure of the firstline treatments. It is also a cost effective technique especially in patients who need repeated endoscopic procedures to handle the stone load especially in developing countries like ours. Laparoscopy also avoids exposure to repeated radiation and removes the stone in Toto in a single sitting with the best stone clearance. Additionally for the urologists this procedure provides the opportunity to develop enough skill for operating laparoscopically in the retro-peritoneum and train himself for more complicated procedures like laparoscopic pyeloplasty, laparoscopic nephrectomy etc.

Conflict of interest: The authors declare they have no conflict of interest

\section{Source of support: Nil}

\section{References}

1. Qingfeng $\mathrm{H}$, Weihong $\mathrm{D}$, Yuancheng $\mathrm{G}$, Yatfaat H, Ke X, et al. (2014) Retroperitoneal Laparoscopic Ureterolthotomy for Proximal Ureteral Calculi in Selected Patients. Sientific World Journal 687876:1-8.

2. Preminger GM, Tiselius HG, Assimos DG, et al. 2007 Guideline for the management of ureteral calculi. Eur Urol 2007;52: 1610-31. 
3. Lopes Neto AC, Korkes F, et al. Prospective randomized study of treatment of large proximal ureteral stones: extracorporeal shock wave lithotripsy versus ureterolithotripsy versus laparoscopy. J Urol. 2012;187:164-168. [PubMed]

4. Park H, Park M, Park T. Two-year experience with ureteral stones: extracorporeal shockwave lithotripsy $\mathrm{v}$ ureteroscopic manipulation. J Endourol. 1998; 12:501-504. [PubMed]

5. El-Moula MG, Abdallah A, El-Anany F, et al. Laparoscopic ureterolithotomy: our experience with 74 cases. Int J Urol. 2008;15:593-597. [PubMed]

6. A. Tefekli, A. Tepeler, T. Akman et al., "The comparison of laparoscopic pyelolithotomy and percutaneous nephrolithotomy in the treatment of solitary large renal pelvic stones," Urological Research, vol. 40, no. 5, pp. 549-555, 2012.

7. Wickham JEA, editor. (ed). The surgical treatment of renal lithiasis. In: Urinary Calculus Disease. New York: Churchill Livingstone; 1979:145-198.

8. Raboy A, Ferzli GS, Laffreda R, et al. Laparoscopic ureterolithotomy. Urology. 1992;39:223-225.[PubMed]

9. Kijvikai K, Patcharatrakul S. Laparoscopic ureterolithotomy: its role and some controversial technical considerations. Int J Urol. 2006;13:206-210. [PubMed]

10. Turk C, Knoll T, Petrik A, et al. EAU guidelines on urolithiasis. Vienna, Austria: European Association of Urology; 2011.

11. D.K. Nigam, Rajesh. Laparoscopic stone surgery for renal and ureteric stones: an evaluation. International Surgery Journal 2016; 3(2): 821-824.

12. Selcuk Sahin, Bekir Aras,Mithat Eksi et al. Laparoscopic Ureterolithotomy. Journal of the Society of Laparoendoscopic Surgeons. 2016; 20(1): 2016.00004.
13. Goel A, Hemal AK. Upper and midureteric stones: a prospective unrandomized comparison of retroperitoneoscopic and open ureterolithotomy. BJU Int2001;88: 679-82.

14. Kane CJ, Bolton DM, Stoller ML. Current indications for open stone surgery in an endourology center. Urology 1995;45:21821.

15. Gaur DD, Trivedi S, Prabhudesai MR, Madhusudhana HR, Gopichand M. Laparoscopic ureterolithotomy: technical considerations and long-term follow-up. BJU Int 2002;89:339-43.

16. Harewood LM, Webb DR, Pope AJ. Laparoscopic ureterolithotomy: the results of an initial series, and an evaluation of its role in the management of uretericcalculi. Br J Urol 1994;74:170-6.

17. Keeley FX, Gialas I, Pillai M, Chrisofos M, Tolley DA. Laparoscopic ureterolithotomy: the Edinburgh experience. BJU Int 1999;84:765-9.

18. Mohamed Gad El-Moula, Adel Abdallah, Fathy El-Anany, Yaser Abdelsalam, Ahmad Abolyosr, Diaa Abdelhameed, et al. Laparoscopic ureterolithotomy: our experience with 74 cases. Int $\mathrm{J}$ Urol 2008;15:593-7.

19. Wolf Jr JS. Treatment selection and outcomes: ureteral calculi. Urol Clin NorthAm 2007;34:421-30.

20. Flasko T, Holman E, Kovacs G, Tallai B, Toth C, Salah MA. Laparoscopic ureterolithotomy: the method of choice in selected cases. J Laparoendosc Adv SurgTech A 2005;15:149-52.

21. El-Feel A, Abouel-Fettouh H, AbdelHakim AM. Laparoscopic transperitoneal ureterolithotomy. J Endourol2007;21:50-4.

22. Hemal AK, Wadhwa SN, Kumar M, Gupta NP. Transperitoneal and retroperitoneal nephrectomy for giant hydronephrosis. J. Urol. 1999;162: 35-9. 